\title{
El carácter fundamental del derecho de las comunidades étnicamente diversas a ser consultadas previamente acerca de las decisiones que afectan sus territorios*
}

\author{
The fundamental character of the right of ethnically diverse communities to be \\ consulted beforehand about the decisions that affect their territories
}

\author{
Maura Lorena Soto Soto \\ Abogada, candidata a magíster en derecho \\ público, Colombia \\ mauralorena23@hotmail.com \\ Johan Steed Ortiz Fernández \\ Abogado, candidato a magíster en derecho \\ público, Colombia \\ johansteedfernandez@hotmail.com
}

Recibido: 12/03/2019 Aprobado: 18/06/2019

DOI: $10.25054 / 16576799.2650$

\section{RESUMEN}

Se analiza el derecho fundamental de las comunidades étnica y culturalmente diversas a ser consultadas previamente sobre las decisiones que afectan directamente el pleno ejercicio de sus derechos, mediante el estudio de las tensiones constitucionales que suscita el goce efectivo del derecho a la consulta previa, en contraste con el ejercicio de la actividad de exploración y explotación de recursos naturales que se enmarcan en el interés económico y general del Estado. En este sentido, se analiza la jurisprudencia constitucional en torno al tema y se explica la controversia desde dos momentos jurídicos relevantes. El primero, en vigencia del Decreto 2655 de $1988^{1}$ y el segundo en vigencia de la Ley 1685 de 2001, nuevo Código de Minas. Se precisa el alcance de la consulta previa, su obligatoriedad, finalidad y otros.

\section{PALABRAS CLAVE}

Comunidades Étnicamente Diversas; Consulta Previa; Cultura; Participación; Territorio.

\section{ABSTRACT}

The fundamental right of ethnic and culturally diverse communities to be consulted beforehand on decisions that directly affect the full exercise of their rights is analyzed. It is made through the study of the constitutional tensions caused by the effective enjoyment of the right to prior consultation, in contrast with the exercise of activities of exploration and exploitation of natural resources that are framed in the economic and general interest of the State. In this sense, the constitutional jurisprudence on the subject is analyzed and the controversy is explained from two relevant legal moments. The first one, in force of the Decree 2655 of 1988 and the second one, in force of the Law 1685 of 2001, new Code of Mines. The scope of the prior consultation, its obligatory nature, purpose, and others are specified.

\section{KEYWORDS}

Ethnically Diverse Communities; Prior Consultation; Culture; Participation; Territory.

\footnotetext{
*Artículo de investigación

1 Este decreto fue derogado por el artículo 361 de la Ley 685 de 2001, publicada en el Diario Oficial $N^{\circ} 44.522$ del 17 de agosto de 2001, fecha de su vigencia. Aclarada en el Diario Oficial No 44.545 del 8 de septiembre de 2001.
} 


\section{INTRODUCCIÓN}

Desde la consagración constitucional del estado colombiano como multicultural, pluralista y diverso mediante la carta política de 1991, el panorama de derechos para las comunidades indígenas y afrodescendientes tomó una mayor relevancia, puesto que comenzó a ser objeto de debate jurídico serio y amplio desarrollo jurisprudencial. Establecer un reconocimiento de rango constitucional en defensa de los derechos de las minorías propició garantías para exigir de forma directa sus derechos, no solo en igualdad de condiciones, sino como sujetos de especial protección constitucional.

Es así como la Corte Constitucional, a partir de la consagración de dichas prerrogativas y en cumplimiento de sus deberes de guardiana de la constitución, se pronunció desde sus inicios en un sentido proteccionista en torno a los derechos de las comunidades indígenas afrodescendientes y otras.

Cabe resaltar que los miembros de dichas comunidades gozan la titularidad de sus derechos fundamentales en dos sentidos: en primer lugar, en razón a su condición de sujetos desde el punto de vista individual $\mathrm{y}$, adicional a ello, constitucionalmente la comunidad en conjunto se reconoce como sujeto de derechos fundamentales (CConst, T-116/2011, H. Sierra). Es decir, no solo se protegen como individuos miembros de la nación, sino que el ordenamiento jurídico salvaguarda y otorga especial protección a grupos étnica y culturalmente diversos en razón a su propia naturaleza y origen.

En este orden de ideas, la Constitución otorga a las comunidades étnicas diversas el ejercicio de facultades normativas y jurisdiccionales dentro de su territorio; les confiere el derecho a gobernarse por autoridades propias según sus costumbres; garantiza el pleno ejercicio a la propiedad colectiva de sus resguardos y territorios; ampara y defiende sus prácticas culturales (CConst, T-116/2011, H. Sierra).

Mediante el presente trabajo se estudia el desarrollo jurisprudencial en torno a la garantía constitucional de las comunidades a ser consultadas previamente, acerca de la viabilidad de proyectos que deriven consecuencias que restrinjan el efectivo goce de sus derechos a un ambiente sano, a la participación en las decisiones que los afectan, a autodeterminarse conforme a sus reglas y costumbres.

En este sentido, se verifican acciones constitucionales ejercidas por distintos grupos de ciudadanos que se han planteado en torno a la dicotomía existente entre el derecho preferente a ser consultados de manera previa en las decisiones que los afectan o limitan el goce de sus derechos, y el ejercicio de actividades que se enmarcan en desarrollo del interés general como ocurre con la práctica de explotación y exploración de recursos naturales.

Desde este panorama, se exponen algunos pronunciamientos representativos de la Corte Constitucional colombiana acerca del rango fundamental de la consulta previa, así como su conexidad con otros derechos fundamentales como el derecho a la vida, a la participación, a la diversidad étnica y cultural, al territorio, al debido proceso, el de la autodeterminación de los pueblos, entre otros.

En este sentido, se analiza la procedibilidad de la accion de tutela para hacer exigible la consulta previa, la obligatoriedad de su realización, se examina su alcance (carácter determinante), y se expone un analisis de las tensiones jurídicas y constitucionales alrededor del ejercicio del derecho a la consulta previa de comunidades étnicamente diversas y las actividades de exploración y explotación de recursos naturales, a partir de dos momentos juridicos determinantes a saber: en primer lugar, en vigencia del D. 2655/1988 y luego a la luz del nuevo Codigo Minero, L.685/2001.

\section{EL DERECHO FUNDAMENTAL DE LAS COMUNIDADES ÉTNICAMENTE DIVERSAS A SER CONSULTADOS PREVIAMENTE FRENTE A DECISIONES QUE AFECTEN DIRECTAMENTE LOS RECURSOS NATURALES Y AMBIENTE DE SUS TERRITORIOS}

A nivel general el reconocimiento del concepto de multiculturalidad de los Estados implica entender que la sociedad no es un simple sistema integrado por personas que comparten una misma visión del mundo, sino que existe un determinado contexto cultural donde pueden interactuar diversos sectores o grupos sociales que pueden tener relaciones conflictivas y no siempre se encuentran en igualdad 
de oportunidades frente a los recursos disponibles (Moreno, 2011).

Por ello, desde la óptica estatal, el reconocimiento de una sociedad diversa cultural y étnicamente requiere la aplicación de unas políticas de inclusión y reconocimiento a determinados grupos que históricamente han sido excluidos o marginados de la estructura social y política del país ${ }^{2}$.

El derecho a la identidad cultural se destaca, entre otras cosas, como componente estructural directamente relacionado a la protección de recursos naturales y del ambiente de territorios, el derecho de las comunidades étnicamente diversas a ser consultadas previamente, mediante procedimientos apropiados, cada vez que se vayan a adoptar medidas susceptibles de afectar sus territorios, valiéndose para ello de las instituciones representativas de su propia estructura y de su organización política (CConst, T-778/2005, M. Cepeda) $)^{3}$.

En Colombia, en dirección de proteger las garantías propias de las minorías, bien sea indígenas, afrodescendientes $\mathrm{u}$ otros, se estableció mediante parágrafo del artículo 330 de la Constitución política que, frente a decisiones relacionadas con la exploración y explotación de los recursos naturales de territorios indígenas, el gobierno propiciará la participación de las respectivas comunidades (CConst, C-891/2002, J. Araujo).

De tal forma, la consulta previa es un derecho fundamental de todas las comunidades, además de indígenas y afrodescendientes, cuyo objetivo consiste en garantizar que los pueblos de estas raíces puedan participar, intervenir y decidir, previamente como su nombre lo indica, en la toma de decisiones que los afectan. Esto quiere decir que se trata de una garantía o mecanismo tan esencial e importante, cuya vulneración implica un serio riesgo para la existencia colectiva y un verdadero peligro en el propósito de conservar y proteger las comunidades de este tipo (Organización Nacional Indígena De Colombia-ONIC, 2011).

Al tenor de las disposiciones de la Corte Constitucional colombiana, se puede definir el derecho a la consulta previa como un elemento inherente a la condición humana de las comunidades étnica y culturalmente diversas (CConst, C-077/2017, L. Vargas) en la medida en que es una exigencia que se deriva de su especial condición y valor histórico natural preferente.

Este hecho implica que la consulta previa en Colombia tenga dos consecuencias jurídicas principales a saber: la primera, es que ante su violación o desconocimiento, sea viable la acción de tutela para defenderla como derecho fundamental y, la segunda, es que eventualmente su vulneración también pueda ser presentada o reclamada ante instancias internacionales en virtud de las obligaciones emanadas de los convenios internacionales suscritos por Colombia que han tenido por objeto el respeto de las culturas históricamente amenazadas (Organización Nacional Indígena De Colombia-ONIC, 2011).

1.1. Consulta previa como garantía de participación de las comunidades étnicas diferentes VS. Ejercicio de la actividad minera como principal fuente de desarrollo del país

Al revisar la jurisprudencia constitucional Colombiana relacionada con la consulta previa, se denota que existe una cantidad considerable de pronunciamientos del máximo órgano en materia constitucional, en torno a una controversia existente entre el ejercicio del derecho de las comunidades a ser consultadas previamente ante decisiones que afecten el pleno ejercicio de otros derechos conexos y el ejercicio de las actividades de exploración y explotación de recursos naturales que involucra sin duda el interés general de la población.

\footnotetext{
2 En otras palabras, la consagración del principio de diversidad étnica y cultural conllevó al reconocimiento de personería a las diferentes comunidades, lo que a su vez les confiere estatus para gozar de sus derechos fundamentales y exigir por sí mismos, su protección cada vez que les sean conculcados.

3 El derecho a la identidad cultural, como un derecho que se deriva del principio a la diversidad étnica y cultural establecido en el artículo 7 de la Constitución, ha sido concebido como un derecho fundamental de las comunidades indígenas y por lo tanto un derecho de naturaleza colectiva (CConst, T-778/2005, M. Cepeda).
} 
Se hallan en contraste diferentes mandatos de orden constitucional: por un lado, la protección a la diversidad cultural, derecho a la consulta previa, derecho a la autodeterminación de los pueblos, derecho a gozar de un medio ambiente sano, mientras que por otro lado, está la garantía del desarrollo sostenible mediante la explotación de recursos naturales (CConst, SU-133/2017, L. Vargas).

Si bien es cierto, la minería en Colombia constituye la principal fuente de recursos, para el desarrollo económico, social, entre otros y, así mismo, deriva el ejercicio de derechos fundamentales conexos a la ejecución de la actividad minera, como son el derecho al mínimo vital, seguridad social, al trabajo. También, resulta evidente que por el impacto en los derechos de los individuos y diferentes comunidades a gozar de un ambiente sano, debe estar regulado de forma rigurosa y cumplir con lineamientos establecidos en respeto del orden social (CConst, SU-133/2017, L. Vargas).

A la hora del ponderar el interés prevalente, la situación no resulta para nada simple si se analiza que se confrontan derechos de distintos grupos poblacionales, que se sustentan intereses igualmente validos pero contrapuestos.

Para dilucidar la situación planteada, se requiere realizar la exposicion a partir de dos momentos juridicos historicos relacionados con el asunto: el primero, en vigencia del D.2655/1988, y una segunda etapa de tensiones constitucionales, en vigencia del nuevo código de minas, L.685/2001.

\subsubsection{Tensiones Constitucionales en vigencia del Decreto 2655 de 1988 relativas al derecho a la consulta previa de comunidades étnicamente diversas y el ejercicio de las actividades exploración y explotación de recursos naturales.}

Resulta importante señalar que en vigencia del D.2655/1988, el panorama es un tanto proteccionista de las minorías, puesto que para resolver tensiones y controversias, prima el argumento con base en el cual no se debe confundir los derechos fundamentales de las comunidades indígenas con los derechos colectivos de otros grupos humanos (CConst, SU-383/2003, A. Tafur).
En vigencia del decreto en cita, para la legitimidad de la actividad minera se requiere que sea autorizada por la autoridad competente, obteniendo el correspondiente registro minero, acreditando el cumplimiento de la totalidad de requisitos contenidos en la normatividad vigente y que, además, se demuestre que con la actividad no se pone en riesgo derechos fundamentales (CConst, T-318/1993, C. Gaviria).

Desde los primeros pronunciamientos de la Corte Constitucional, relacionados con la consulta previa, es posible entrever el espíritu proteccionista que ha procurado dicho tribunal en favor de las comunidades étnicamente diversas. Verbigracia, mediante sentencia de revisión de tutela número 428 de 1992, la corte analiza el caso de los integrantes de un resguardo indígena quienes solicitan vía tutela la protección de su derecho fundamental a la vida y a la propiedad que se ve conculcado por la construcción de un tramo de carretera, cuya obra se reputa de interés general (CConst, T-428/1992, C. Angarita).

Para el caso particular, la Corte profundizó que el hecho de que ciertas obras contribuyan al desarrollo $\mathrm{y}$, por ende sean consideradas construcción de interés general, no puede valer como argumento suficiente para justificar el desencadenamiento de daños a la comunidad (Assies y Guillén, 2001). Por ende, señaló que el Estado, o los particulares, no pueden afectar el ambiente natural de manera indiscriminada sin tener en cuenta las circunstancias propias del sitio $\mathrm{y}$ de sus pobladores.

De acuerdo con el fallo de la Corte, cuando se pretende solucionar el conflicto presentado entre el interés general y otro tipo de intereses con protección constitucional, la solución debe ser encontrada de acuerdo con los elementos jurídicos que proporcione el caso concreto y a la luz de los principios y valores de rango constitucional cuya labor de interpretación es función primordial del juez y en especial de la propia Corte Constitucional (CConst, T-428/1992, C. Angarita).

En observancia del caso particular, se evidencia que el interés de la Corte consiste primordialmente en privilegiar las garantías otorgadas a los grupos étnicos y culturalmente diversos, por considerar que poseen una legitimación mayor que el interés 
general de la sociedad colombiana que se vería beneficiada con la construcción de la que trata el caso sub examine.

Pese a lo anterior, es importante resaltar que, en torno a la discusión planteada entre derechos de comunidades y explotación de recursos naturales en sus territorios, la Corte Constitucional también reconoce que prevalece la 'función social de la propiedad', aun cuando esta haya sido concedida a particulares para su explotación económica, por lo cual, eventualmente, dicha actividad debe generar una redistribución en las riquezas que se generan a partir de su ejercicio, de modo que se cumpla con dicho fin (CConst, SU-133/2017, L. Vargas).

Lo anterior significa que, en vigencia del D. 2655/1998, pese a que la Corte reconoce que ante la controversia entre el derecho de las comunidades a participar y ser consultados previamente, y la prevalencia del interés general, la solución está en manos del juzgador, a quien le corresponde ponderar los derechos e intereses y fallar según los principios y valores de rango constitucional.

Durante la vigencia del D. 2655/1998 prima el argumento bajo el cual el Estado sigue siendo propietario de los recursos naturales no renovables, sin distinguir entre aquellos que se encuentran en el suelo y los que provienen del subsuelo y $\sin$ discriminar tampoco entre los que se hallan en suelo de propiedad privada respecto de los que se localicen en terrenos públicos. Es decir, los recursos naturales no renovables son de propiedad pública con independencia del lugar en que se encuentren, por lo cual, el interés público que caracteriza a la industria minera faculta al Estado para declarar la prescripción del dominio teniendo como objeto el prevalecimiento del interés general (CConst, C-216/1993, J. Hernández).

\subsubsection{Interpretación de la consulta previa en vigencia del nuevo Código de minas, Ley 685 de 2001.}

Se procede ahora a analizar la tensión o controversia central teniendo en cuenta los cambios que suscitó la entrada de vigencia del actual Código de Minas.

La Ley 685 de 2001, cuyo propósito de expedición general fue alcanzar la protección efectiva del medio ambiente y el logro de un desarrollo económico sostenible cuando de explotación de los recursos minerales se trate (Millán, Niño, Rincón, y Rojas, 2009), destaca fines primordiales, entre algunos:

(i) fomentar la exploración de los recursos mineros teniendo en cuenta que su aprovechamiento se realice en forma armónica con los principios y normas de explotación racional de los recursos naturales no renovables, así como "dentro de un concepto integral de desarrollo sostenible";

(ii) que en los trabajos de exploración minera, debe establecerse el impacto que sobre el medio ambiente y el entorno social puedan causar. Y que, en todo caso, tales actividades exploratorias deben acomodarse a las "normas y guías adoptadas por el Gobierno";

(iii) que las autoridades ambientales a quienes compete otorgar la autorización a que se refiere la norma acusada deben ejercer las funciones de evaluación, control y seguimiento ambiental de las actividades de exploración de los recursos naturales no renovables, que generen o puedan generar deterioro ambiental, y que función comprende la expedición de la respectiva licencia ambiental;

(iv) que, en ejercicio de esta función, según la misma ley, dichas autoridades deben tomar medidas de prevención y protección del medio ambiente (CConst, C-813/2009, J. Pretelt).

Es importante señalar que, en vigencia de la nueva legislación, se otorga una especial importancia a la participación de la comunidad en las decisiones que se adopten cuando se trate de realizar la explotación de recursos naturales en territorios indígenas. De este modo, el derecho fundamental de la comunidad a preservar la integridad se garantiza y efectiviza a través del ejercicio de otro derecho que también tiene el carácter de fundamental, como es el derecho de participación de la comunidad en la adopción de las referidas decisiones (CConst, T418/2002, A. Tafur).

Esto concuerda con lo dispuesto en el parágrafo del artículo 330 constitucional, el cual establece que

La explotación de los recursos naturales en los territorios indígenas se hará sin 
desmedro de la integridad cultural, social y económica de las comunidades indígenas. En las decisiones que se adopten respecto de dicha explotación, el Gobierno propiciará la participación de los representantes de las respectivas comunidades (CP., 1991, Art. 330).

Ahora bien, otro aspecto relevante de la Ley 685 de 2001, es que prevé la delimitación y alinderamiento de zonas mineras indígenas como un mecanismo para proyectar un régimen especial de exploración y explotación de los recursos naturales yacentes en el suelo y el subsuelo de los territorios, con lo que una vez más se constituye garantía del derecho a la participación del pueblo y las comunidades étnicamente diversas (CConst, T-418/2002, A. Tafur).

En efecto, mediante la delimitación de "zonas mineras indígenas" ${ }^{4}$ se reconoce sobre el respectivo territorio un derecho de prelación para exploración y explotación frente a otros posibles explotadores.

En razón a ello, toda propuesta que implique afectación a dichas zonas será resuelta con la participación de los representantes de las respectivas comunidades indígenas (CConst, $\mathrm{T}$ 418/2002, A. Tafur).

\section{PROCEDIBILIDAD DE LA ACCIÓN DE TUTELA PARA EL AMPARO DEL DERECHO A LA CONSULTA PREVIA DE LAS COMUNIDADES ÉTNICAMENTE DIVERSAS}

De los primeros pronunciamientos de la corte frente al tema, se puede resaltar que existió una interesante controversia entre dos posiciones distintas.

Por un lado, se encuentra la posición mediante la cual se afirma que la vía de tutela es el único mecanismo que garantiza plenamente el derecho constitucional de las comunidades a ser consultadas sobre las decisiones que los afectan en cuanto a su territorio se refiere. Mientras que, por otra parte, se encuentra la opinión contrapuesta bajo la cual se estima que existen otros mecanismos de protección de derechos colectivos, mediante los cuales se puede hacer efectivo dicho derecho.

Según esta última tendencia, la acción de tutela debe reservarse única y estrictamente a derechos de categoría fundamental, de acuerdo al texto constitucional, y el derecho de las comunidades a ser consultados previamente puede ser exigido mediante las acciones previstas para la defensa de derechos colectivos.

En la sentencia T-428 de 1992, uno de los primeros pronunciamientos del alto tribunal frente al tema, se hayan las dos posiciones contrapuestas a las que se hace referencia (CConst, T-428/1992, C. Angarita).

Como se mencionó anteriormente, la situación fáctica de la tutela gira en torno al caso de los integrantes de un resguardo indígena quienes solicitan la protección de su derecho fundamental a la vida y a la propiedad que se ve conculcado por la construcción de un tramo de carretera, cuya obra que se reputa de interés general (CConst, $\mathrm{T}$ 428/1992, C. Angarita).

Si bien es cierto que en dicho pronunciamiento la procedencia de la acción de tutela no obedece al amparo de la consulta previa como derecho fundamental propiamente dicho, sino que se da con ocasión de evitar un perjuicio irremediable, sin duda el fallo posee una relevancia incalculable, en la medida que denota cómo la Corte, desde sus primeros pronunciamientos, en aras de evitar que se consume la vulneración de derechos fundamentales de comunidades especialmente protegidas, resuelve tutelar los derechos invocados (CConst, T-428/1992, C. Angarita).

De tal forma, es posible afirmar que las pretensiones de la comunidad fueron atendidas por vía de tutela, en razón a que la Corte encuentra que lo peticionado tiene sustento en derechos fundamentales ampliamente protegidos por la constitución y por ende exigibles mediante dicha acción constitucional.

4 Las zonas mineras indígenas son sectores que se establecen dentro de un territorio indígena (CConst, T-418/2002, A. Tafur) 
Por otra parte, en la misma sentencia está la posición contraria que expone que no es procedente la acción constitucional de tutela para la protección de estos derechos (CConst, T-428/1992, C. Angarita).

Se trata de la posición del magistrado José Gregorio Hernández Galindo quien expone, mediante aclaración del voto, que la acción de tutela es improcedente ya que, según su concepto, la situación fáctica encaja mejor dentro de las acciones populares para la protección de los derechos e intereses colectivos. Afirma, en este sentido, que los asuntos analizados en el caso no deberían ser objeto de protección vía acción de tutela ya que esta institución ha sido concebida con otros fines, específicamente relacionados con la protección de los derechos fundamentales considerados en sentido estricto (CConst, T428/1992, C. Angarita).

Más adelante, mediante sentencia de unificación de jurisprudencia numero 039 De 1997 M.P. Antonio Barrera Carbonel, se dilucida cualquier duda respecto de la procedencia de la acción de tutela para la protección del derecho a la consulta previa (CConst, SU-039/1997, A. Barrero).

En el caso, la Corte tuteló el derecho fundamental a la consulta previa de una comunidad indígena ante la acción del recién creado Ministerio de Medio Ambiente que había otorgado licencia ambiental a una multinacional para realizar actividades de explotación de hidrocarburos en áreas del resguardo de la comunidad, sin llevar a cabo un proceso previo de consulta (CConst, SU039/1997, A. Barrero) (CConst, T-800/14, G. Mendoza).

La sentencia representa, en la evolución jurisprudencial, todo un hecho histórico en la medida que reconoce de manera expresa que la consulta previa es un derecho fundamental por sí mismo, dada su especial significación para la subsistencia de los pueblos indígenas, en tanto entraña también el derecho a la participación mediante los mecanismos pertinentes en las decisiones que puedan afectarlos (CConst, SU039/1997, A. Barrero).
La participación de las comunidades en las decisiones que pueden afectarlas en relación con la explotación de los recursos naturales, ofrece como particularidad el hecho de que la referida participación, a través del mecanismo de la consulta, adquiera la connotación de derecho fundamental, en la medida en que se erige como un instrumento básico para preservar la integridad étnica, social, económica y cultural de las comunidades y para asegurar, por ende, su subsistencia como grupo social (CConst, SU039/1997, A. Barrero).

Siguiendo lo expuesto anteriormente, es claro que debido a que no existe, en el ordenamiento jurídico colombiano, un mecanismo distinto a la acción de tutela para que los pueblos indígenas reclamen ante los jueces la protección inmediata de su derecho a ser consultados, a fin de asegurar su derecho a subsistir en la diferencia, basándose en el artículo 86 de la Constitución, es la tutela el mecanismo para la protección de estos derechos fundamentales (CConst, SU-039/1997, A. Barrero) ${ }^{5}$.

\section{FINALIDAD DEL DERECHO DE LAS COMUNIDADES ÉTNICAMENTE DIVERSAS A SER CONSULTADOS PREVIAMENTE SOBRE LAS DECISIONES QUE LOS AFECTAN, ALCANCE DE LA CONSULTA Y OTROS}

La consulta previa de las comunidades indígenas se sustenta en el Convenio 169 de la OIT y también en el parágrafo del artículo 329 de la C.P. que dice: "En caso de que este territorio decida constituirse como entidad territorial, se hará con el cumplimiento de los requisitos establecidos en el inciso primero de este artículo". Uno de los requisitos es la "participación de los representantes de las comunidades indígenas", exigida precisamente por el Convenio (CConst, T634/1999, A. Martínez).

\footnotetext{
5 La corte ha destacado que el derecho fundamental a la consulta previa tiene sustento constitucional en la visión pluralista de la sociedad colombiana, en la adopción de medidas especiales, de carácter favorable, frente a grupos vulnerables o personas en condición de debilidad manifiesta; en la diversidad étnica que prescribe el respeto de las diferencias culturales como elemento constitutivo del Estado y en el mandato que rechaza la imposición de la forma de vida mayoritaria (CConst, T-652/1998, C. Gaviria)
} 
De acuerdo con la jurisprudencia de la Corte Constitucional, existen subreglas atinentes a la finalidad de la institución de la consulta a las comunidades étnicas, signadas por el mutuo respeto y la buena fe entre comunidad indígena y las autoridades públicas, así:

a) Que la comunidad tenga un conocimiento pleno sobre los proyectos destinados a explorar o explotar los recursos naturales en los territorios que ocupan o les pertenecen, los mecanismos, procedimientos y actividades requeridos para ponerlos en ejecución.

b) Que igualmente la comunidad sea enterada e ilustrada sobre la manera como la ejecución de los referidos proyectos puede conllevar una afectación o menoscabo a los elementos que constituyen la base de su cohesión social, cultural, económica y política y, por ende, el sustrato para su subsistencia como grupo humano con características singulares.

c) Que se le dé la oportunidad para que libremente y sin interferencias extrañas pueda, mediante la convocación de sus integrantes $\mathrm{o}$ representantes, valorar conscientemente las ventajas y desventajas del proyecto sobre la comunidad y sus miembros, ser oída en relación con las inquietudes y pretensiones que presente, en lo que concierna a la defensa de sus intereses y, pronunciarse sobre la viabilidad del mismo. Se busca con lo anterior, que la comunidad tenga una participación activa y efectiva en la toma de la decisión que deba adoptar la autoridad, la cual en la medida de lo posible debe ser acordada o concertad (CConst, SU-383/2003, A. Tafur).

En ese orden de ideas, es necesario que se cumplan las directrices mencionadas, que se presenten fórmulas de concertación o acuerdo con la comunidad, y que finalmente esta manifieste, a través de sus representantes autorizados, su conformidad o inconformidad con dicho proyecto y la manera en cómo se afecta su identidad étnica, cultural, social y económica (Gaviria, 2005).

Ahora bien, las entidades estatales tienen la obligación de garantizar el goce efectivo a la participación, brindando toda la información que no goce de reserva constitucional o legal; dicha información debe ser completa, consistente, coherente, verificable, comparable, contextualizada, diáfana y siempre oportuna. Desde luego que el derecho a la información, así servido, se convierte en poderoso instrumento de reflexión-acción tanto individual como colectiva, en el entendido de que las autoridades estatales, además de esa información, deben asumir la promoción, creación y fomento de las condiciones idóneas a la discusión pública de los temas pertinentes, recordando, a la vez, que la participación ciudadana en esos ámbitos de discusión constructiva supone el recíproco respeto de los criterios expuestos por los interlocutores institucionales y privados, pero no pasivamente, sino reedificando mutuamente sobre la comprensión de lo ya examinado y depurado de manera concertada, al tiempo que la diferencia y pluralidad de opiniones actualizan su poder constructivo en el suceso democrático (CConst, C891/2003, J. Araujo).

En ese sentido, será preciso indicar que el valor de consulta no se iguala a la información o notificación que se le hace a la comunidad indígena sobre un proyecto de exploración o explotación de recursos naturales. Luego, toda decisión inconsulta, artificial, engañosa, meramente informativa, adoptada de mala fe o inapropiadamente, no se entiende como consulta previa y, en cambio, configura una vulneración del derecho fundamental de las comunidades a ser consultadas (CConst, C-35/2016, G. Ortiz).

La falta de cumplimiento de cualquiera de las obligaciones constituirá una vulneración del derecho a la consulta previa y dará paso a que se proceda legítimamente a la suspensión o terminación -si es del caso- de los trabajos.

Además de la consulta previa y el consentimiento, hay garantías que debe prestar el Estado y los concesionarios al momento de considerar los planes de "infraestructura o desarrollo"; entre otras, permitir la participación y compartir de forma razonable los beneficios del proyecto con el pueblo o la comunidad étnica que sea directamente afectada (CConst, T-129/2011, J. Palacio) (CConst, T-172/2013, J. Palacio).

Por tanto, la contraparte, sea de naturaleza pública o privada, debe facilitar la identificación plena de 
la afectación o perjuicios, rendir informes consistentes y verídicos sobre los alcances de la obra, proyecto o labor y cumplir cabalmente con los compromisos que se hayan pactado con las comunidades (CE, rad. 2290/2016, C.P. A. Namén).

Ahora bien, partiendo del supuesto del hecho de que la comunidad indígena, afrodescendiente o étnicamente diversa, ha sido consultada previamente para estudiar la viabilidad del desarrollo de una obra o proyecto, cabe hacerse la pregunta ¿Qué sucede si dicha comunidad no está de acuerdo con las entidades estatales competentes acerca de admitir o rechazar la adopción de un proyecto de alto impacto para el interés general? (CConst, C-077/2017, L. Vargas) ¿Tienen derecho las comunidades a oponerse a la realización del proyecto o la adopción de la medida que permite el desarrollo de una obra cuando estas afectan presuntamente sus intereses particulares?

En principio, y en concordancia con los instrumentos normativos y amplio desarrollo jurisprudencial en torno al tema, se puede deducir que en el evento de que no se logre un acuerdo en el ejercicio del derecho a la consulta previa, el proyecto de desarrollo o las medidas que se pretendan adoptar, por regla general no deberían proseguirse o, por lo menos, que no se continúen hasta tanto se logre verificar que los riesgos que supone la actividad a desarrollar no contrarían derechos inherentes y fundamentales de las comunidades directamente implicadas (Organización Nacional Indígena De ColombiaONIC, 2011).

Como se ha analizado hasta ahora, en razón a que a las comunidades indígenas, afrodescendientes y étnicamente diversas se les ha investido de autonomía preferente, tienen el derecho a definir el futuro de sus intereses y decisiones con base en sus propias convicciones, y este es precisamente el objeto y ámbito que el derecho a la consulta previa involucra (Organización Nacional Indígena De Colombia-ONIC, 2011).

Sin embargo, es preciso aclarar que pese a la obligatoriedad de la consulta previa, lo determinado por la misma no implica per se un alcance absoluto.

Ante este panorama, para aclarar la situación, es necesario recurrir al artículo 332 constitucional, que establece que el Estado es dueño de los recursos naturales no renovables independientemente del lugar en el que se encuentren, bien sea suelo, subsuelo o incluso en propiedad privada, lo cual se fundamenta en el interés público propio de la actividad minera y la prevalencia del interés general (CConst, C216/1993, J. Hernández).

Paradójicamente, los últimos pronunciamientos del Tribunal Constitucional guardan una relación de identidad con el argumento que imperó durante la vigencia del Decreto 2655 de 1988, consistente en que el derecho a la consulta previa no es absoluto, pues si bien la Constitución ordena que se propicie la participación de las respectivas comunidades en los asuntos relacionados con la exploración y explotación de recursos naturales en los territorios indígenas, de ninguna manera puede entenderse que deba necesariamente llegarse a un acuerdo como requisito sine qua non para radicar el proyecto (CConst, C-891/2002, J. Araujo).

Conforme a lo anterior, por principio general, el Gobierno está obligado a propiciar mecanismos efectivos y razonables de participación en los asuntos que afecten a las comunidades indígenas. Sin embargo, si no se llega a un acuerdo con estas últimas, no tiene por qué frenarse el proceso legislativo en asuntos que a la vez son de interés general, como ocurre en el caso minero (CConst, C-216/1993, J. Hernández).

De acuerdo con la jurisprudencia colombiana, en casos en que no sea posible el acuerdo o la concertación, la solución recae en el Estado quien, con sus acciones, debe propender a la protección de la identidad social, cultural y económica de la comunidad. La decisión de la autoridad debe estar "desprovista de arbitrariedad y de autoritarismo; en consecuencia, debe ser objetiva, razonable y proporcionada a la finalidad constitucional" (CConst, SU-383/2003, A. Tafur). A su vez, ello implica que deben arbitrarse los mecanismos necesarios para mitigar, corregir o restaurar los efectos que las medidas de la autoridad produzcan o puedan generar en detrimento de la comunidad o de sus miembros (CConst, C-216/1993, J. Hernández).

En igual sentido, la Corte ha señalado que: Si adelantadas las consultas de buena fe y de una manera apropiada a las circunstancias no se logra el consentimiento de los pueblos 
consultados acerca de las medidas propuestas, las entidades accionadas deberán evaluar, en lo que a cada una de ellas concierne, la gravedad de las lesiones individuales y colectivas que se causen con las medidas, a fin de implementarle al programa los correctivos que sean necesarios para salvaguardar a las personas, sus bienes, instituciones, trabajo, cultura y territorio (CConst, SU$383 / 2003$, A. Tafur $)^{6}$.

Finalmente, resulta conveniente precisar que el alcance del derecho de las comunidades a ser consultadas previamente a la realización de un proyecto que afecte su territorio implica el cumplimiento de tres características indispensables (CConst, C-216/1993, J. Hernández):

(i) la participación real y efectiva en relación con los asuntos que afectan a las comunidades, particularmente respecto de la explotación de recursos naturales yacentes en sus territorios (CConst, C216/1993, J. Hernández.);

(ii) los mecanismos de participación no pueden limitarse a cumplir una simple función informativa (CConst, C216/1993, J. Hernández); y

(iii) dichos mecanismos, particularmente el derecho de consulta previa, deben desarrollarse de buena fe, de manera apropiada a las circunstancias y con miras a alcanzar un acuerdo o lograr el consentimiento de las comunidades acerca de las medidas legislativas propuestas (CConst, T-376/2012, M. Calle).

\section{CONCLUSIONES}

Sin duda el ordenamiento jurídico colombiano ha reconocido la prevalencia de los derechos de las minorías, bien se trate de comunidades indígenas, afrodescendientes u otras. Desde el reconocimiento del Estado multicultural con la constitución de
1991, el panorama de derechos de estas minorías tomó gran relevancia. A lo largo de poco menos de treinta años, la Corte Constitucional ha actuado en defensa de la subsistencia y permanencia de estos grupos diferenciados de individuos.

Es posible decir, frente al derecho fundamental que les asiste a las comunidades étnica y culturalmente diversas a ser consultados previamente sobre decisiones que puedan afectar el normal goce de sus derechos y garantías primordiales, que el gobierno colombiano ha precisado medidas para diferenciar, de entre otro tipo de derechos, los que le pertenecen a esta parte de la población. En este sentido, se ha mantenido hasta ahora una línea de respeto y protección estatal en torno a los derechos de las comunidades étnica y culturalmente diversas, que propicia la subsistencia de formas e identidades distintas.

Sin embargo, como se expuso, ante la controversia entre el ejercicio de la participación de las comunidades, su derecho a ser consultados previamente, y las actividades de exploración y explotación de recursos naturales, queda bajo criterio del fallador determinar de acuerdo a las circunstancias particulares del caso, a la luz de los principios y valores constitucionales el interés tutelar. Como quedó claro, partiendo de que se ha respetado el derecho a la consulta previa, dentro de los lineamientos señalados, la decisión tomada por la comunidad consultada carece de fuerza determinante. Esto significa que una vez realizada

la consulta, pese a que no se llegue a un acuerdo con la comunidad, se podrán adelantar los proyectos y obras, con la obligación a cargo de quien realiza el aprovechamiento de los recursos naturales, de mitigar el impacto negativo, lesiones individuales o colectivas y socializar y brindar información.

\footnotetext{
6 Ante esta controversia, la jurisprudencia constitucional ha precisado que el gobierno puede echar mano de, por ejemplo, talleres preparatorios que tengan por objeto forjar el consentimiento completo, libre, previo e informado de las comunidades indígenas afectadas, a partir de los cuales se procure y gestione, de buena fe, un consenso real y lo más universal posible alrededor de la medida legislativa (CConst, T-376/2012, M. Calle)
} 
Nos queda un panorama de desconsuelo al analizar uno de los fallos más recientes donde la Corte Constitucional, a nuestro parecer, tiene un retroceso en materia de protección de derechos de las comunidades y, sobre todo, del medio ambiente. La sentencia es de suma relevancia además porque desconoce la voluntad del constituyente primario, cuando declara que la consulta popular realizada a los habitantes de Cumaral Meta, quienes rechazaron las explotaciones mineras y petroleras dentro de su territorio, no tiene fundamento constitucional y legal, y por ende accede a las pretensiones de la Compañía petrolera MANSAROVAR (CConst, SU-095/2018, C. Pardo), tutelando los derechos al debido proceso y acceso a la justicia, recurriendo al fundamento bajo el cual las decisiones sobre explotaciones mineras y petroleras en el territorio correspondiente al subsuelo le pertenece es a la Nación y, por ende, es el Estado quien tiene la última palabra sobre la explotación de los recursos del subsuelo. Finalmente, el fallo invita al poder legislativo a reglamentar el mecanismo de conciliación con las comunidades en aras de propiciar su participación.

Si bien es cierto, a diferencia del caso precitado, el presente artículo analiza desde diferentes perspectivas el derecho de las comunidades a ser consultadas previamente ante una decisión que los afecte $y$, si bien su naturaleza difiere evidentemente de una consulta popular, de lo resuelto por el Tribunal Constitucional cabe preguntarnos, adelantándonos un poco a futuros pronunciamientos, si quizá en determinada oportunidad $¿$ Puede la corte privilegiar la actividad económica y desarrollo de la actividad minera en cabeza del Estado por encima de los derechos de minorías y demás? Sin duda ello conllevaría a un importante giro en la tendencia decisional que en esta materia se ha dado.

Queda la posibilidad de suponer, que en la misma tendencia, la Corte decida privilegiar el interés económico y general del Estado y, en la misma línea decisional que tomó al definir la controversia entre la compañía Mansarovar y los habitantes de Cumaral, desconozca los avances que se han tenido en materia de participación y ejercicio de derechos de las comunidades étnicamente diversas.

También, puede que la suposición que hacemos corresponda a una visión pesimista, que se deriva de la incertidumbre que origina el reciente y controvertido pronunciamiento de la Corte $\mathrm{y}$, en lugar de modificarse el precedente, se mantenga en el mismo sentido proteccionista en favor de las diferentes comunidades étnicas. De todas formas, lo único que sí es cierto, es que las realidades y los contextos varían y fluctúan en función del tiempo e intereses que existan en determinada época o de acuerdo a nuevas tendencias de la globalización o muchos factores que pueden variar y, como en el caso analizado de la consulta previa de CumaralMeta, dar un giro inesperado a la jurisprudencia e incluso a la legislación.

Por ahora será cuestión de permanecer atentos a lo que en adelante determine la Corte. En este sentido, queda abierta la discusión; existe un amplio cúmulo de posiciones jurídicas renovadas que muy seguramente entrarán a determinar el futuro de los pronunciamientos de las Altas Cortes.

\section{REFERENCIAS BIBLIOGRÁFICAS}

I. Assies, W., y Guillén, R. (2001). El reconocimiento de los derechos indígenas: jurisprudencia Colombiana y propuestas sobre la jurisdicción indígena en Ecuador y Bolivia. Colegio de Michoacán. Centro de Estudios Rurales. Disponible en https://vdocuments.mx/documents/el -reconocimiento-de-los-derechosindigenas.html

II. Colombia. Constitución Política de Colombia (1991). Artículo 330.

III. Colombia. D. 2655/1988. Por el cual se expide el Código de Minas. 23 de diciembre. D.O. núm. 38.626.

IV. Gaviria, J. (2005). Qué son, cuáles son y cómo se protegen los derechos culturales. Disponible en https://www.monografias.com/trabaj os88/que-son-como-se-protegenderechos-culturales/que-son-como- 
se-protegen-derechos-

culturales 3. shtml

V. Millán, C., Niño, M., Rincón, J., y

Rojas, P. (2009). Protección a la consulta previa: derecho fundamental de las minorías contra el interés colectivo. Disponible en: https://docplayer.es/46234204-Jueze-interpretacion-constitucionalpresentado-por-camilo-millan-mariaisabel-nino-juan-carlos-rinconpaula-rojas-fajardo.html

VI. Moreno, H. A. (2011). Derechos diferenciados y Estado multicultural en Colombia. Disponible en: http://viva.org.co/cajavirtual/svc028 7/pdfs/articulo783 287.pdf

VII. Organización Nacional Indígena De Colombia-ONIC. (2011). El derecho fundamental a la consulta previa de los Pueblos Indígenas en Colombia. Disponible en: https://www.onic.org.co/canastadesa beres/113-

cds/publicaciones/derechos/1880-elderecho-fundamental-a-la-consultaprevia-de-los-pueblos-indigenas-en$\underline{\text { colombia }}$

\section{REFERENCIAS JURISPRUDENCIALES}

VIII. CE, rad. 2290/2016, C.P. A. Namén (Consejo de Estado 30 de agosto de 2016). Radicado: 11001-03-06-0002016-00057-00(2290).

IX. CConst, T-778/2005, M. Cepeda.

X. CConst, C-077/2017, L. Vargas.

XI. CConst, SU-133/2017, L. Vargas

XII. CConst, SU-383/2003, A. Tafur

XIII. CConst, T-318/1993, C. Gaviria.

XIV. CConst, T-428/1992, C. Angarita.

XV. CConst, T-116/2011, H. Sierra.

XVI. CConst, C-813/2009, J. Pretelt.

XVII. CConst, T-418/2002, A. Tafur.

XVIII. CConst, SU-039/1997, A. Barrero.

XIX. CConst, T-800/14, G. Mendoza.

XX. CConst, T-652/1998, C. Gaviria.

XXI. CConst, T-634/1999, A. Martinez.

XXII. CConst, C-35/2016, G. Ortiz.

XXIII. CConst, T-129/2011, J. Palacio.

XXIV. CConst, T-172/2013, J. Palacio.

XXV. CConst, C-216/1993, J. Hernández.

XXVI. CConst, C-891/2002, J. Araujo.

XXVII. CConst, T-376/2012, M. Calle. 